OPEN ACCESS

Volume: 9

Special Issue: 1

Month: May

Year: 2021

E-ISSN: 2582-1334

Received: 28.04.2021

Accepted: 05.05.2021

Published: 10.05.2021

Citation:

Erarslan, Ali. "Correlation between Metadiscourse, Lexical Complexity, Readability and Writing Performance in EFL University Students' Research-Based Essays." Shanlax International Journal of Education, vol. 9, no. S1, 2021, pp. 238-254.

DOI:

https://doi.org/10.34293/ education.v9iS1-May.4017

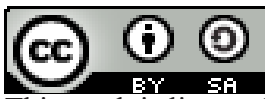

This work is licensed under a Creative Commons Attribution-ShareAlike 4.0 International License

\section{Correlation between Metadiscourse, Lexical Complexity, Readability and Writing Performance in EFL University Students' Research-based Essays}

\author{
Ali Erarslan \\ Alanya Alaaddin Keykubat University, Turkey \\ (D) https://orcid.org/0000-0003-2536-6044
}

\begin{abstract}
Metadiscourse is a tool for writers to guide and interact with readers through texts. Yet in most student texts, one of the points lacking is the interaction between writers and readers. In this study, frequency and type of interactive and interactional metadiscourse features were explored via students' research-based essays based on Hyland's metadiscourse taxonomy. Additionally, the students' English Vocabulary Profile (EVP), lexical diversity, lexical density, and readability features of the texts in the corpus were scrutinized, which serve as an indicator of writing quality. Finally, the relationship of metadiscourse use with students' writing performance, lexical diversity, lexical density, and readability was explored through statistical measures. Findings show that following explicit metadiscourse instruction, students' research-based essays included more interactive metadiscourse than interactional metadiscourse, indicating that the students were dealing with more textual features, such as coherence, than interactional metadiscourse. Apart from findings regarding EVP such as lexical diversity, lexical density, and readability features, a positive relationship was explored between metadiscourse use and writing performance, lexical components, and textual features. It is concluded that metadiscourse should be integrated into the writing syllabus since it has a positive relationship with students' use of academic vocabulary in their essays. Keywords: Metadiscourse, Lexical features, Academic writing performance
\end{abstract}

\section{Introduction}

Second language writing has come into prominence especially due to necessities brought about by international exams, study-abroad programs, and mobility transactions (Yi, 2009). This is particularly recognized in the academic world yet writing is a difficult language skill to learn in English as a Second Language (ESL) contexts (Akdemir \& Eyerci, 2016; Fareed et al., 2016). This difficulty, as acknowledged by Hyland (2003), is based upon the requirement to produce well-formed, cohesive texts with appropriate use of lexical items together with correct grammar. As Hyland (2009) explains, the difficulties faced by learners of English may also stem from the way they were taught to write in their first language (henceforth L1), task difficulties, lack of feedback, and language proficiency in the target language (henceforth L2). L2 writing is also essential for university students since the academic world requires students to write effectively in English when partaking in academic tasks such as examinations, essays and reporting the results of research findings or while writing a thesis. Thus, writing is a priority for deal with the more challenging aspects of university life (Hyland, 2013; Sağlamel \& Kayaoğlu, 2015). Writing for academic purposes and in academic settings, which is known generally as academic writing, addresses the needs of both research academics and the students at universities. 
Within English for Academic Purposes (EAP), the writing skill is generally associated with having several characteristics in terms of the writer's adherence to objectivity, preciseness, and formality (Hyland \& Jiang, 2017). Since one of the major objectives of academic or research writing is to disseminate information and inform readers within the worldwide academic community, the core genres in the field are journal articles, scientific studies or reporting scientific knowledge and findings (Barton \& Mcculloch, 2018; Davaei \& Karbalaei, 2013; Nasiri, 2013). According to Hyland and Tse (2004), in such genres there exists a social interaction between the reader and the writer known as metadiscourse, the purpose of which is to provide successful communication for the delivery and comprehension of relevant academic discourse. Thus, writers seek ways to make their texts understood clearly and be accepted by the readers (Amiryousefi \& Rasekh, 2010) by delivering their intended meaning based on the given context (Alotaibi, 2019). In fact, they need to gather ideas and present them to their readers by polishing them in their writing to make readers comprehend the content best (Huda \& Gumilang, 2019). That is, the author tries to construct a social relationship with the readers to attract their attention so that they follow the text, thereby fulfilling the readers' expectancies (Alavinia \& Zarza, 2012; Hyland \& Tse, 2004).

Although defined as 'discourse about discourse' (Katelyn, 2017; Vande Kopple, 1985), metadiscourse has currently moved beyond this definition and is seen as the writer's way of using expressions to construct meaning within a text to attract and guide readers, thereby enabling the writer to fully deliver the intended message. It also involves the writer's reflections about the subject matter (Hyland, 2010; Hyland \& Tse, 2004). Thus, a concise understanding of metadiscourse consists of the interactional and interactive roles of a writer (Kafes, 2017) and refers to the text-related aspects that connect ideas and logically organize the discourse. Besides this, such aspects mark the writer's attitude regarding the content of the text and the readers as a community. Understanding the expectations, needs, and interests of readers in a discourse community requires the writer to possess the necessary knowledge regarding genre, content, attitude, and style (Almacioğlu \& Okan, 2019; Hyland, 2009). To cement the relationship between text and reader, writers make use of metadiscourse markers to position themselves by delivering their intended message; interpreting, supporting or opposing an idea as well as interacting with the readers in the target community (BalGezegin, 2016; Cubukcu, 2017).

In terms of second language writing, integrated writing has gained considerable attention in the field of second language writing both in ESL and EFL contexts (Zhang, 2015). Integrating writing with other language skills, especially with reading, is based upon the idea of developing not only writing or other related skills but also arising from the nature of writing itself (Plakans \& Gebril, 2017). Integrated academic writing deals with the processing of source materials, which requires effective reading skills. Thus, considering the significance of integrated writing, teaching it for academic purposes may be inferred as being a necessity for students who receive an education at universities since they have to be able to produce written texts based on the knowledge they have acquired via their reading.

A well-written text exhibits some fundamental features in terms of unity, coherence and cohesion, and as such, the aim is to have the readers process a text effectively. To provide this, apart from metadiscourse, the use, variety and density of the lexical items in a text, also known as lexical complexity (LC) (Ginting, 2018), may affect the readability of the text. Lexical features contained in a text contribute to coherence and cohesion in that, by selecting the appropriate vocabulary or lexical reiteration, the connection between the lines and ideas are presented clearly (Akbulut, 2018; Rashtchi \& Baniardalani, 2019).

Lexical density refers to the ratio of a text's content words to its function words (Gregori-signes \& Clavel-arroitia, 2015; Ishikawa, 2015; Johansson, 2008) and lexical diversity is a measure of the variety and range of words written in a text (McCarthy \& Jarvis, 2007). According to Johansson (2008), the density of lexis in a text is related to the quality of the writing as well as the informative aspects contained in that text. As for lexical diversity, it is the proportion of both content and functional 
lexical items to the token, a total number of words as calculated by LexDiv: Words (functional and content words) x 100/total token (Ginting, 2018; Ishikawa, 2015; McCarthy \& Jarvis, 2007, 2010). Both lexical density and lexical diversity measurements give an insight into text quality, cohesion, informative quality, and lexical easiness. For students to produce a well-structured written text, the range of their vocabulary is significant since vocabulary knowledge is positively correlated with writing performance (Kiliç, 2019). Currently, one of the most common measures of students' grasp of vocabulary is the English Vocabulary Profile (henceforth EVP). EVP is a corpus-based glossary taking its roots from the Cambridge Learner Corpus, and is a project run by Cambridge University, the British Council, and Council of Europe that takes the Common European Framework of Reference for Languages (henceforth CEFR) and defines level descriptors from A1 to C2 (Sun, 2017). In Turkey, the foreign language proficiency of students is also based on the CEFR, and language levels in all segments of education across the country comply with the CEFR descriptors, including their vocabulary knowledge.

The use of metadiscourse markers in written texts has gained increasing attention from researchers (Hyland \& Tse, 2004; Jones, 2011; Katelyn, 2017; Kim \& Lim, 2013; Lin, 2005; Vasheghani Farahani, 2018). In Turkey too there have been several studies focused on the use of metadiscourse markers across different text types and genres (Akbas, 2012; Akbas \& Hatipoğlu, 2018; Bal-Gezegin, 2016; Can \& Yuvayapan, 2018; Demir, 2017; Ozdemir \& Longo, 2014; Yüksel \& Kavanoz, 2018; Yuvayapan, 2019). A majority of the research studies focused on metadiscourse in different parts of scientific texts such as the abstract, conclusion, and discussion (Akbas, 2012; Mansouri, Najafabadi, \& Boroujeni, 2016; Ozdemir \& Longo, 2014). Additionally, student-created text types such as argumentative or opinion paragraphs and essays were also examined in many studies (Anwardeen et al., 2013; Babanoğlu, 2014; Çandarli et al., 2015; Jones, 2011; Uysal, 2012).

In the context of this current study, studies conducted in Turkey show that Turkish writers of English use interactional metadiscourse and interactional metadiscourse markers with changing frequencies. Additionally, the texts produced in English by Turkish learners/authors reflect less coherent and cohesive features due to some reasons such as the L1 effect or cultural background (Akbas, 2012; Akbas \& Hatipoglu, 2018; Can \& Yuvayapan, 2018; Çandarlı et al., 2015; Ozdemir \& Longo, 2014).

As seen in the related literature, the significance of using metadiscourse markers is undeniable (Alotaibi, 2018; Hyland \& Tse, 2004). Hyland (2005) acknowledges that understanding the use of metadiscourse markers is helpful in two aspects. Firstly, learners gain an insight into the cognitive aspects required to process a text; and following this it aids writers to make use of effective ways to help readers process the text. Also, learners as writers, upon gaining awareness of metadiscourse, can position themselves for their ideas and engage these ideas with their readers by negotiating them throughout the text making use of metadiscourse markers.

As stated previously, the studies focusing on student-generated texts mainly investigated opinion or argumentative writing, yet research-integrated texts produced by university English Language Teaching (ELT) students were not studied in the literature. Thus, analyzing students' researchintegrated essays as a genre in the field of academic writing is believed to be significant for several reasons. Initially, students in the ELT department, as prospective language teachers, have the task of learning academic writing for academic purposes during their university education. In this respect, their understanding of academic writing, encompassing research writing and related genres, is of great significance for their future teaching practice. Also, these students may continue to pursue an academic career and may work as researchers and academic personnel, which necessitates that they write academic articles. The findings of a study regarding ELT students' metadiscourse use in combination with other textual elements may shed light on the influence of course instructors and program designers within the academic community and allow them to make any necessary adjustments in their teaching practice. Finally, among metadiscourse studies, 
student produced-texts are gaining popularity; however, as a type of academic writing, researchbased essays have not been studied in the literature although in most universities students have to write such essays for various purposes including project writing or graduation thesis. Thus, all these issues highlight the need for the present study.

As Olinghouse and Wilson (2012) explain, the variety of lexical items in a text is a strong indicator of writing quality. When studies focusing on metadiscourse are analyzed, it is seen that students' writing performance, lexical diversity, readability, and metadiscourse relations have not been studied in detail. These are the factors that contribute to the overall quality of texts in the academic field. Thus, the lack of one or more of these elements may decrease readability and cause a failure in getting the message across. In order to fill these gaps in the literature, this study aims to investigate English Language Teaching (ELT) department students' use of metadiscourse markers in research-integrated writing texts in an EFL setting by also analyzing the relationship between the students' use of metadiscourse markers, their writing grades and lexical diversity, and the readability scores of students' texts.

To gain a comprehensive insight into the ELT learners' use of metadiscourse markers in research-integrated essays in parallel with the lexical dimension of EFL writing by exploring the relationship between lexical diversity and EFL writing proficiency, this study seeks to answer the following research questions;

1. What are the metadiscourse features of Turkish ELT students' research-integrated texts?

2. What are the lexical and textual features of Turkish ELT students' research-integrated texts in terms of EVP, lexical diversity, lexical density, and readability?

3. What is the relationship individually and overall, between metadiscourse, students' writing performance, lexical diversity, lexical density, and readability scores in research-based academic writing?

\section{Method}

\section{Corpus and Procedure of the Study}

The students in ELT departments in Turkish state universities are placed with an English proficiency at
B2 level based on CEFR results equivalent to 6 and 6.5 in IELTS and a 72-93 score band in TOEFL IBT. However, prior to being accepted at any university, they have to pass (and achieve a sufficient score in) a nationwide language exam in English consisting of grammar, vocabulary, and reading sections (Ozturk \& Aydin, 2019) and are not assessed with regards to their communication skills in terms of listening, speaking, and writing. Thus, they need to take courses in three major domains - content, pedagogical and content-pedagogical - in their pre-service phase of training to become effective language teachers.

In terms of writing skills, freshmen students in ELT departments across the country need to take "Advanced Writing I" and "Advanced Writing II" courses; the content of which is based on "paragraph writing" in the former and "essay writing" in the latter. In each course, they are required to write paragraphs and essays of various types and on different topics. The course duration is 28 weeks per teaching year. Each week, students receive a two-hour writing assignment based on different paragraph and essay types. In the first half of the teaching year, the course aim is to equip learners with the fundamentals of second language writing and paragraph types. In the second half, the aim is the mastery of writing skills with various essay types such as comparisoncontrast, opinion, or research-based essay writing.

Regarding the results of this study, during their first semester in Advanced Writing I course 78 students failed to produce acceptable papers or those with a lack of unity, coherence, and cohesion. The texts produced in the form of paragraph writing by the students in the first semester were analyzed for errors under seven categories based on the rubric used for evaluation as: structure, spelling, punctuation, coherence, cohesion, use of appropriate lexical items and paragraph organization. Following the four-stage procedure of Ellis (1994) for the analysis of errors, student-produced opinion paragraphs at the end of the first semester were collected and sample paragraphs were chosen for each student in which errors were analyzed, identified, and classified following the evaluation of the errors. A total of 78 opinion paragraphs (141 tokens in average per paragraph) were analyzed for the errors as seen in Table 1. 
Table 1 Distribution of Student Errors in Paragraph Writing

\begin{tabular}{|l|c|c|}
\hline & $\boldsymbol{f}$ & $\mathbf{\%}$ \\
\hline Coherence & 2872 & 26.8 \\
\hline Cohesion & 2529 & 23.6 \\
\hline Structure (grammar, syntax) & 1848 & 17.2 \\
\hline Paragraph organization & 1093 & 10.2 \\
\hline Use of lexical items & 986 & 9.2 \\
\hline Spelling & 718 & 6.7 \\
\hline Punctuation & 685 & 6.3 \\
\hline
\end{tabular}

As seen in Table 1, despite students trying hard to produce good papers, they failed to write effective paragraphs although they appeared to write grammatically correct sentences. As they had unity, coherence and cohesion-related L2 writing problems (resulting in low grades), they could neither develop nor connect their ideas throughout the text when writing. This study was not designed as an experimental one for two major reasons: Initially, in the first half of the education year, they were given instruction based on paragraph writing and their writing scores were quite unsatisfactory. Next, since the second half of the education year would be based on essay writing, both pre-test and post-test scores would not be reliable for the reason that the course content would be different between the first and the second semesters. Also, based on error analysis of the paragraph writing, the most frequent errors belonged to coherence and cohesion and lack of metadiscourse use; thus, they had to be given explicit instructions concerning the use of metadiscourse and the aspects contributing to textual features associated with metadiscourse.

Since the course content included researchbased writing, all these concerns would best reflect the effects of explicit metadiscourse instruction by combining it with extensive research reading. For this purpose, the students had to gain an understanding of the concept of metadiscourse and metadiscourse markers in writing. The researcher, as the course instructor, changed the whole course syllabus for the second teaching term and added metadiscourse markers, their functions, and uses. While doing so, Hyland's metadiscourse categories and uses of metadiscourse markers under the interactional and interactive categories were embedded in the course content including ethical aspects, giving citations and references. Students worked on texts and analyzed the metadiscourse markers in academic texts. Additionally, the course content was based upon integrated reading and writing in combination with research-based essay writing. During the instruction, the students were introduced to how to make use of research findings to support their ideas and use them in their texts when referencing text in the APA 6.0 citation style. The writing topics were carefully chosen and required students to undertake an extensive reading of available texts, articles, or internet sources and to make use of these scientific texts as a source in their research-based writing. They then needed to submit an academic paper at the end of the spring semester as a final project. Thus, at the end of the spring semester of 2018-2019 teaching year, a corpus of 58,746 tokens was compiled from a total of 78 research-based essays with given topics.

\section{Analysis of the Data}

For metadiscourse, various taxonomies were put into practice (Crismore, Markakanen \& Steffensen, 1993; Dafouz-Milne, 2008; Hyland, 2005). However, Hyland's taxonomy of metadiscourse is still considered to be one of the most reliable and detailed (Alavinia \& Zarza, 2012; Ebrahimi, 2018). In the taxonomy of metadiscourse offered by Hyland (2005), there are two major categories, interactive category and interactional category. The interactive category is divided into five sub-sections listed as transitions, frame markers, endophoric markers, evidentials, and code glosses, which according to Hyland, help the writer to organize the discourse by taking the readers' needs and expectations into account. The interactional category consists of hedges, boosters, attitude markers, self-mentions, and engagement markers. The interactional category of metadiscourse deals with engaging the reader by revealing the writer's stance concerning the information proposed and is directed towards the reader (Hyland, 2005; Hyland \& Tse, 2004). As Alotaibi (2018) explains, the interactive category of metadiscourse helps the writer to produce a discourse that is both well organized and coherent. Meanwhile, the interactional category helps to build an interaction between the readers and the producer of the text. 
Table 2 A model of Metadiscourse in Academic Texts (Hyland, 2015).

\begin{tabular}{|c|c|c|}
\hline Category & Function & Examples \\
\hline Interactive & Help to guide reader through the text & \\
\hline Transitions & $\begin{array}{l}\text { express semantic relation between main } \\
\text { clauses }\end{array}$ & in addition / but / thus / and \\
\hline Frame markers & $\begin{array}{l}\text { refer to discourse acts, sequences, or text } \\
\text { stages }\end{array}$ & finally / to conclude / my aim is \\
\hline Endophoric markers & refer to information in other parts of the text & $\begin{array}{l}\text { noted above / see Fig / in section } \\
1\end{array}$ \\
\hline Evidentials & $\begin{array}{l}\text { refer to source of information from other } \\
\text { texts }\end{array}$ & $\begin{array}{l}\text { according to } \mathrm{X} /(\mathrm{Y}, 1990) / \mathrm{X} \\
\text { states }\end{array}$ \\
\hline Code glosses & $\begin{array}{l}\text { help readers grasp meanings of ideational } \\
\text { material }\end{array}$ & $\begin{array}{l}\text { namely /e.g./such as / in other } \\
\text { words }\end{array}$ \\
\hline Interactional & Involve the reader in the argument & \\
\hline Hedges & $\begin{array}{l}\text { withhold writer's full commitment to } \\
\text { proposition }\end{array}$ & might / perhaps / possible/about \\
\hline Boosters & $\begin{array}{l}\text { emphasize force or writer's certainty in } \\
\text { proposition }\end{array}$ & in fact / definitely / it is clear that \\
\hline Attitude markers & express writer's attitude to proposition & $\begin{array}{l}\text { unfortunately / I agree/ } \\
\text { surprisingly }\end{array}$ \\
\hline Engagement markers & $\begin{array}{l}\text { explicitly refer to or build relationship with } \\
\text { reader }\end{array}$ & $\begin{array}{l}\text { consider / note that / you can see } \\
\text { that }\end{array}$ \\
\hline Self-mentions & explicit reference to author(s) & I / we / my / our \\
\hline
\end{tabular}

While analyzing student texts, metadiscourse markers and lexical complexity, including lexical density and diversity as well as readability, were taken into consideration. In the analysis of student essays, both manual annotation and UAM Corpus Tool 3.3 were utilized. The reason for making use of both the manual method and a corpus tool to analyze metadiscourse was to eliminate false annotations. In fact, some results were manually controlled by checking student essays one-by-one looking for interactive and interactional categories. To exemplify, all occurrences of "and" could be included as a metadiscourse marker in the corpus tool, if they were used to connect two lexical items or two phrases rather than as a transition marker at the discourse level that needed to be omitted. Additionally, in relational markers, self-mentions may represent the roles of originator, recounter, guide, or opinion-holder, yet roles such as originator could contribute to the writer's voice (Tand \& John, 1999). For this reason, the pronoun "you" was analyzed closely, and those occurrences intended to relate the writer with the reader, such as the role of originator, were manually included in the analysis.

For students' lexical proficiency, EVP was used as a base, and lexical diversity in student essays was investigated by both VocD and the Measure of Textual Lexical Diversity (henceforth MTLD) (McCarthy \& Jarvis, 2007, 2010). For lexical density, an online resource "http://www.analyzemywriting. com" was used, and for the readability scores of student essays, Flesch Reading Ease score and Flesch-Kincaid readability measures were utilized. Statistical analyses were conducted using the data set compiled by calculating each student's essay in terms of metadiscourse markers, achievement scores, and other textual features. For the correlation between students' writing proficiency and textual features in terms of the use of metadiscourse markers, and textual and lexical complexity, Pearson productmoment correlation coefficient was run.

It is worth noting here that student texts were graded based on a rubric involving task achievement, coherence and cohesion, lexical resource, grammatical range and accuracy. Two independent assessors were involved in the scoring process of 
the student texts through a constant comparison data analysis process. The reliability of the assessors was provided by Cohen's Kappa as a measurement of the degree of agreement between raters, and found to be highly reliable (.80).

\section{Findings}

Depending on the research questions, the first analysis was conducted on the students' metadiscourse markers. For this, the corpus was analyzed in terms of the interactive and interactional categories, with their sub-categories, based on Hyland's taxonomy.

Findings Regarding Metadiscourse use in Students' Research-based Essays

In terms of the interactive category of metadiscourse, "transitions", "frame markers", "endophoric markers", "evidentials" and "code glosses" were analyzed based on their frequency per 1000 words, as shown in Table 3.

Table 3 Use of Interactive and Interactional Metadiscourse Markers in this Study

\begin{tabular}{|l|c|l|c|}
\hline $\begin{array}{c}\text { Interactive } \\
\text { Metadiscourse }\end{array}$ & $\mathbf{f} / \mathbf{1 0 0 0}$ & $\begin{array}{c}\text { Interactional } \\
\text { Metadiscourse }\end{array}$ & f/1000 \\
\hline Transitions & 23 & Hedges & 6 \\
\hline Frame markers & 14 & Boosters & 4 \\
\hline Endophoric & 3 & Attitude Markers & 5 \\
\hline Evidentials & 7 & $\begin{array}{l}\text { Engagement } \\
\text { Markers }\end{array}$ & 9 \\
\hline Code glosses & 5 & Self-Mentions & 7 \\
\hline
\end{tabular}

Based on the analysis of the interactive metadiscourse, the findings clearly show that students predominantly made use of transitions, also known as "logical connectives", in their texts $(\mathrm{f}=26)$. Among these, "and" was the most-used connective with a frequency of 13 followed by "because" $(\mathrm{f}=5)$, and "but" ( $\mathrm{f}=5)$. The least-used was "therefore", with only three occurrences. Apart from transition markers, the other most-frequently utilized subcategory of interactive metadiscourse was frame markers $(\mathrm{f}=14)$. Within frame markers, different aspects indicating sequencing, stages, shifts and announced goals in the student-produced texts were taken into consideration, and markers indicating sequencing such as "first", "second, "last" etc. were found to be the most commonly used ( $f=7)$. Label markers such as "in conclusion", "to repeat" were the next most commonly utilized frame markers with a frequency of four. The rest were shared between announce goals and topic shifts.

Since the essays the students had to produce required extensive reading and research-based reporting to support their stances throughout their writing, the use of evidentials would be significant to observe that students were able to use scientific and research-based information to reflect their points of view, following the APA reference system. Thus, a close investigation with regards to student use of evidentials within interactive metadiscourse proved that they employed 10 different types of evidential such as "according to", "point out", "studies" ( $\mathrm{f}=7$ ). Code glosses and endophoric markers were the leastfrequently used interactive metadiscourse markers. Among code glosses, "for example", "for instance", and "which means" were the most utilized ones. However, endophoric markers were employed the least in student essays, with an occurrence of three.

Findings regarding interactional metadiscourse show that ELT students employed interactional markers with engagement markers the most. This shows that students wanted to build a relationship with the readers in their texts. The next mostcommonly used interactional metadiscourse was self-mentions, with an occurrence of seven. Within this sub-category, the use of "our" and "we" ranked the highest and "I" and "me" the least. This shows that students tried to connect with their readers. Apart from these, hedges were used with a frequency of six, with five different types such as "might", "may", "possible", "maybe", etc. Prioritizing hedges following relation-building and self-mentioning throughout the texts, students made use of attitude markers ( $\mathrm{f}=5$ ) involving a number of adjectives like "important", "remarkable", "interesting", etc. to indicate their position regarding the topic or idea. Finally, the least-frequently used interactional metadiscourse was found to be boosters, with an occurrence of four, of three different types such as "should", "know" and "the fact that".

To gain a deeper insight into the metadiscourse 
markers in the corpus compiled, student use of interactive and interactional metadiscourse markers was compared, as in Figure 1.

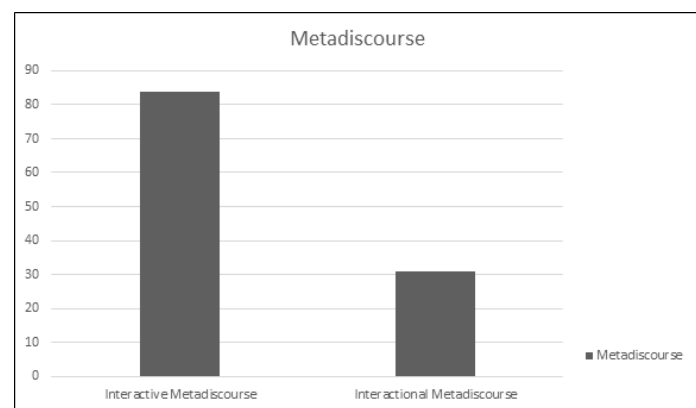

Figure 1 Comparison of Frequency of Interactive and Interactional Metadiscourse

It is seen that the ELT students' use of interactive metadiscourse was more than interactional metadiscourse. Although interactional metadiscourse by which the writers established a relationship with the reader via markers in the text was evident, interactive metadiscourse use was far more dominant in the corpus of the study. However, it is worth noting here that apart from the high-frequency use of transitions in the interactive category, students employed both interactive and interactional metadiscourse similarly in terms of occurrence. Thus, transitions were preferred by the students most in their texts, unbalancing the likely equality in the use of both categories.

\section{Findings Regarding Textual and Lexical Features of the Student Texts}

As one of the basic components of text quality, the lexical features in students' research-based writing essays were analyzed in terms of EVP, lexical diversity and lexical density, as well as the readability of these texts, as shown in Tables 4 and 5 below.

\section{EVP of the Students}

The student-produced essays were examined to reveal which words were known and used by the students based on language levels specified according to CEFR. To analyze the vocabulary profiles of the students, each text was examined and it was seen that the students made use of words ranging in level from A1 to $\mathrm{C} 2$. Yet, when investigated in more detail, the majority of texts contained words falling between levels A1 and B2.

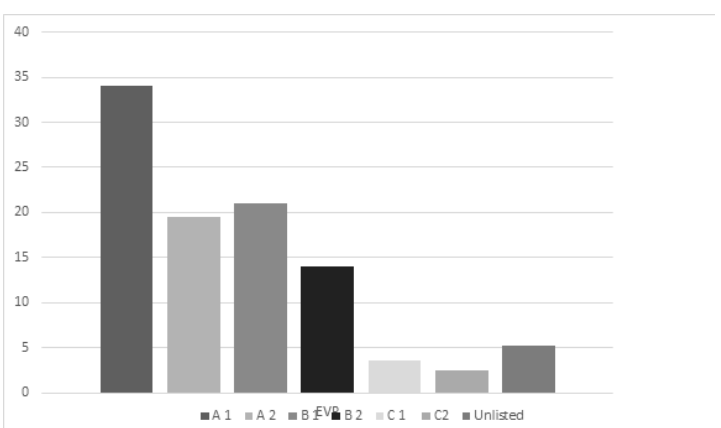

Figure 2 EVP-Lexical Range of Students (\%) in this Study

As novice academic writers in their first year of university, students made use of words mainly at A1 level with a percentage of $34.0 \%$ (Figure 2). Considering that most common or high-frequency words fall into A1 level, the main indicator of the students' vocabulary intensity based on CEFR levels would be to look at their use of vocabulary items within other levels. It is clear that the words employed in student essays ranged from A2 (19.5\%) to $\mathrm{C} 2(2.5 \%)$. However, $\mathrm{C} 1$ and $\mathrm{C} 2$ level vocabulary items in student texts were quite low $(\mathrm{C} 1: 3.6 \%$ and C2: $2.5 \%$ ) when compared to levels between A1 and B2. In general, it is clear that the vocabulary knowledge of the students as the writers of the corpus compiled for this study ranged mainly from A1 to B2. In fact, the vocabulary knowledge of the students was satisfactory in reflecting their ideas and opinions in research-based essays. Considering that students are placed into English language teaching departments with B2 levels, vocabulary usage at C1 and $\mathrm{C} 2$ levels would be demanding for students in their first year of university education.

\section{Findings Regarding Lexical Density, Lexical Diversity and Readability Scores}

Vocabulary richness, namely lexical diversity, is a significant indicator of how well language learners utilize their active vocabulary as an indicator of high-quality academic writing. In the study, two existing measures, VocD and Measure of Textual Lexical Diversity (MTLD) as proposed by McCarthy and Jarvis (2010), were used to find out the lexical 
diversity. The findings regarding lexical diversity in terms of VocD show that the mean score of student texts was 95.14 and the D estimate ranged between 51.42 (lowest) and 128.58 (highest). The $\mathrm{D}$ estimate regarding the students' lexical richness shows that students employed varied and expansive lexical items in their written works as a key element of their written fluency. Similarly, due to reliability concerns, MTLD was also applied to the lexical diversity analysis, which also supported the analysis findings of index D, indicating that the students' existing vocabulary use in their essays was rich enough and varied.

Table 4 Lexical Diversity, Lexical Density and Readability Scores

\begin{tabular}{|l|c|c|c|}
\hline & Min & Max & Mean \\
\hline VocD & 51.42 & 128.58 & 95.14 \\
\hline MTLD & 42.36 & 136.92 & 76.13 \\
\hline LexDen & 45.71 & 65.4 & 56.70 \\
\hline Flesch Reading Ease & 20.3 & 62.82 & 46.87 \\
\hline Flesch-Kincaid Grade & 8.06 & 96.67 & 12.22 \\
\hline
\end{tabular}

Concerning lexical density, the analysis of the texts as seen in Table 4 shows that the lexical density of the student-produced texts was between 45.71 (lowest) and 65.4 (highest) with a mean score of 56.70 out of 2121 count types. It can be said that the mean score of students' lexical density was within the average range suggested by Ure (1971), as being over 40. To assess the textual quality of student texts, readability scores were also investigated via the Flesch-Kincaid readability test consisting of Flesch Reading Ease and FleschKincaid Grade, two common readability measures.
Since Flesch Reading Ease consists of a 100-point scale, low scores on the readability test indicate that the text is difficult to process for understanding. The mean score for Flesch Reading Ease in the studentproduced texts was 46.87 , showing that the essays were satisfactory, since the 30-50 band in the Flesch Reading Ease test is described as "difficult to read", indicating that the text difficulty for understanding addresses an advanced level of users of the language, which is also appropriate for undergraduate students (To et al., 2013). The second measure for scoring readability, Flesch-Kincaid Grade, also indicates that the readability of the texts based on a mean score of 12.22 ranging from 8.06 to 96.67 addresses $\mathrm{C} 1$ level readers. Thus, the findings, in general, show that the students produced research-based essays with rich and dense lexical features to transmit their intended message within the academic genre.

\section{Findings Regarding Correlations between Metadiscourse, Student Performance in Writing, Readability Scores, Lexical Density and Lexical Diversity}

One of the major aspects that this study sets out to establish is a set of in-text relationships to determine the quality of a text, affecting its understandability by readers as well as demonstrating the author's competence in writing. The students' performance in research-based writing, the use of metadiscourse, readability scores, and lexical richness and lexical density in these texts were analyzed to investigate correlations. To do this, Pearson analysis was utilized to determine the relationship between the variables mentioned.

Table 5 Pearson Correlation Coefficients of Variables

\begin{tabular}{|l|c|c|c|l|}
\hline & $\begin{array}{c}\text { Total } \\
\text { Metadiscourse }\end{array}$ & $\begin{array}{c}\text { Writing } \\
\text { Performance }\end{array}$ & Readability & LexDiv \\
\hline Total Metadiscourse & 1 & & & \\
\hline Writing Performance & $.84^{* *}$ & 1 & & \\
\hline Readability & $.28^{*}$ & $.31^{* *}$ & 1 & \\
\hline Lexical Diversity & $.32^{* *}$ & $.29 * *$ & -.048 & 1 \\
\hline Lexical Density & .04 & -.02 & .18 & .15 \\
\hline $\mathrm{p}<0.01^{* *}, \mathrm{p}<0.05 *$, Readability (Flesch-Kincaid Grade), LexDiv (Lexical Diversity, \\
VocD), Lexical Density, n=78 \\
\hline
\end{tabular}


Table 5 shows that a positive relationship was found between metadiscourse markers' use and students' writing performances, $\mathrm{r}=0.84, \mathrm{n}=78, \mathrm{p}$ $=0.001$. It turns out that students with better writing performance make appropriate use of metadiscourse markers and can interact with both the text and the readers through the text. Also, when the readability scores of student texts are examined, there is again a positive relationship between metadiscourse use and the readability scores, $\mathrm{r}=0.28, \mathrm{n}=78, \mathrm{p}=0.005$. Likewise, the writing performance of the students has a positive correlation with the readability scores of the research-based essays produced by these students, $\mathrm{r}=0.31, \mathrm{n}=78, \mathrm{p}=0.001$. Students with high readability text scores also scored high in writing performance.

The texts produced by the students were also examined in terms of lexical diversity. When the relationship between metadiscourse use and lexical diversity is examined, there is a positive relationship between metadiscourse and the lexical richness of the students $(\mathrm{r}=0.32, \mathrm{n}=78, \mathrm{p}=0.001)$. At the same time, as Table 4 demonstrates, there is also a positive relationship between lexical diversity and writing performance $(r=0.29, n=78, p=0.001)$. Findings in detail show that although metadiscourse use is positively related to the students' writing performance, readability scores, and lexical diversity, there is no statistically significant relationship between lexical diversity and readability $(\mathrm{r}=-0.48)$. To summarize, lexical density has no correlation with any of the variables analyzed in this study.

\section{Discussion and Conclusion}

This study addressed the metadiscourse, textual and lexical features of student-produced researchbased essays to investigate the relationship between the textual and lexical aspects in the texts. Turkish students in an EFL setting were placed into the ELT department as a result of having a high level of English language proficiency determined by a grammar- and reading-based national exam. Yet, these same students failed to produce coherent and cohesive texts in the form of paragraphs. Noticing students' L2-related writing problems through error analysis, the course syllabus was changed by the author and the significance and use of metadiscourse markers were introduced to the students. Also, the course content was fine-tuned to be in line with the academic needs of the students as novice researchers. Offering the academic course content these ELT students were given essay topics that required reading extensively about the topic and using the research findings to support their ideas in the texts. By collecting a total of 78 research-based essays from the students, a corpus of 58,746 tokens was compiled and analyzed for the aims of this study.

The first research question in the study aimed at exploring interactive and interactional metadiscourse, based on Hyland's classification. In terms of the interactive category of metadiscourse, more use of transition markers in student essays was made compared to other metadiscourse markers. Earlier studies had similar findings to the current study (Anwardeen et al., 2013; Hyland \& Tse, 2004; Yüksel \& Kavanoz, 2018); the use of transitions was found to have the highest frequency among other markers of metadiscourse. Regarding transition use in the findings of this study, the most frequently used tokens were "and", "but" and "because". As Sancak (2019) explained in her study, Turkish university students found the use of these transitions markers easy. Also, the use of "and" was addressed in other studies showing that, as an additive marker, "and" was the most frequent token dominating all other transition markers and metadiscourse markers, observed not only in L2 but also L1 writers (Ho \& Li, 2018; Yüksel \& Kavanoz, 2018; Dumlao \& Wilang, 2019; Akbas, 2012). Thus, the token "and" is utilized and observed in the texts of both users of the language (L1 and L2) as a feature providing text coherence.

Regarding the dominant use of transition markers in student-written texts, Hyland (2005) states that transitions are the most frequent metadiscourse markers since writers directly elucidate their reasoning without causing ambiguity. As one of the salient findings of this study, the intense use of transition markers and use of "and" are consistent with the findings of earlier studies (Akbas, 2012; Sancak, 2019; Vasheghani Farahani, 2018) and can be claimed to be common to most writings in different contexts produced by researchers or students in L1 and L2. 
Similarly, the use of frame markers was the second most frequent in the interactive category. Yüksel and Kavanoz (2018) also found that following transition markers, frame markers were the second most frequent subcategory. Among the frame markers, the tokens reflecting "sequencing" within the texts were the most dominant, while markers announcing the purpose of the writer were the least frequent. Considering the writing course content in Turkish universities, students start to learn writing in L2 via paragraph organization. The effectiveness of an academic text is dependent upon careful development and organization of ideas within the text and as Sonntag and Mclaughlin (1984) stated, it is critical for the students to learn proper text organization. Thus, the intense use of sequencing markers under the subcategory of frame markers reflects the course content to which students were exposed in their writing course. Minimal use of goal markers within frame markers also supports this, since goal announcing does not specifically take a place in most writing course content.

In total interactive and interactional categories, the least frequently employed subcategory was endophoric markers. Low frequent use of endophoric markers in student essays can be explained by lack of knowledge referring to information in other parts of the texts. It is also true that in other studies which focused on student essays, the lowest frequency in terms of metadiscourse use belonged to endophoric markers (Gholami et al., 2014; Yüksel \& Kavanoz, 2018).

In terms of interactional metadiscourse, the most frequently utilized subcategory in students' texts was engagement markers and this indicates that they try to communicate with their readers and try to establish a close relationship with them. As Akbaş (2012) states, reader engagement is a significant element in writing contributing to successful communication between the writers and authors. This indicates that the students in this current study made use of more engagement markers in their texts to communicate with their readers, which contributes to their text quality in terms of building rapport between the endusers of the texts. Additionally, engagement marker utilization in texts is a clear sign of the writer's awareness of the readers and the writer's desire to go into the detail, to elucidate, to guide the readers, and to interact with them. Thus, taking Hyland's (2005) explanation about engagement markers into account, it can be said that the students, as the writers of the corpus used in this study, were aware of their readers and had reader-oriented reasons for making use of these engagement markers. At the same time, the second most frequent subcategory within interactional metadiscourse belonged to selfmentions, indicating a deliberate authorial stance in their texts. According to Hyland and Tse (2004), by making use of self-mention markers writers are able to build up a scholarly identity to support their ideas and claims.

When the findings for interactive and interactional metadiscourse use were compared, interactional metadiscourse use was less frequently utilized due to the overuse of transition markers in the interactive category. In the literature, fewer studies compare both categories of metadiscourse since a large majority of corpus studies focused mostly on only one category. As explained by Vasheghani Farahani (2018) and Hyland (2005), interactive metadiscourse use is an indicator of a writer dealing with textual features to help particular readers, and interactional metadiscourse is the readers' involvement with the text by the writer in addition to making the text coherent and well organized. Considering the comparatively more frequent use of interactive metadiscourse, it is seen that the students, as novice research writers, focused more on text organization to explicitly establish their intended meaning while also addressing the readers through less frequent use of interactional metadiscourse.

Most studies conducted on metadiscourse in various contexts support the findings of the current study. Akbaş (2012) found that Turkish writers of English utilized more interactive resources compared to interactional metadiscourse. Similarly, Vasheghani Farahani (2018) found that writers of research articles in Applied Linguistics made use of more interactive metadiscourse, with the highest occurrences being transitions and frame markers. Considering that the writers of the corpus used in this study and the writers of the corpus used in Vasheghani Farahani's study were language-related users, these findings overlap with each other, 
indicating that language related writers' texts are well-organized and coherent.

Thus, it can be concluded that coherence-related problems observed in the earlier texts produced by students were mainly eliminated by creating awareness by adding explicit metadiscourse elements into the writing course content. Overall, it can also be concluded that to make effective use of metadiscourse markers, reserving a place for metadiscourse in the course syllabus and introducing students to the significance and functions of metadiscourse markers increases their use in student texts, thus contributing to the coherence, cohesion, and processing of essays. This is also believed to increase their competency of writing in English for academic purposes. Hence, metadiscourse features should be prioritized within the writing course syllabus for learners of English, especially for novice research writers in academic contexts within EAP.

Another point addressed in this study was the lexical features of the students' research-based essays. For this, the EVP, lexical diversity, lexical density, and readability of the texts were analyzed. In terms of lexical diversity indicating the lexical richness of the student texts, both VocD and MTLD were utilized in the analysis due to text length concerns. Although these two measures are relatively good for assessing lexical richness, criticism of the VocD measurement tool has gained momentum because of its tendency to be affected by the length of the text, in that texts containing between 100-500 tokens would give the best lexical diversity measure. However, LD measures for texts falling outside these ideal ranges would be less reliable (McCarthy \& Jarvis, 2010).

Although the average essay length in the corpus used in this study was 753 tokens, MTLD was utilized in addition to VocD for lexical diversity. As indicated by some studies in the literature (Johansson, 2008; Koizumi, 2012), MTLD is least affected by text length, and texts longer than 100 words would be best for MTLD. The lexical diversity indices for this study indicated that students employed a rich array of lexical items in their essays $(\mathrm{VocD}=95.14$; MTLD =76.13). As Duran, Malvern, Richards and Chipere (2004) explain, a text having an average VocD value of 80-105 would have the typical features of an academic text and student essays can be considered to represent the features of an academic text in terms of the lexical diversity (Bérubé et al., 2018; Koizumi, 2012; Koizumi \& In'nami, 2012; McCarthy \& Jarvis, 2007, 2010). Additionally, the EVP measure showed that, based on CEFR descriptors, the students' vocabulary profile ranged between levels $\mathrm{A} 1$ to $\mathrm{C} 2$, indicating that students were proficient users of the language in terms of their language proficiency.

When analyzed in detail, both EVP and lexical diversity measures, conducted separately, overlap with each other in this study, providing reliability of these dependent scores. If EVP addressed lower proficiency levels, lexical diversity measures would contradict with the EVP findings. As Kyle (2019) reports, there is a positive relationship between lexical diversity and language proficiency. Thus it can be concluded that high lexical diversity measures may also indicate a higher level of lexical proficiency based on CEFR, which is one of the specific findings of this study.

Lexical density was also assessed and findings indicate that the research-based essays written by ELT students were lexically dense, which shows that these texts addressed a particular group of readers using high language proficiency. On the other hand, lexical density is not necessarily a sign of language proficiency. A text with high lexical density may be addressing a lower level of readers and be associated with lower language proficiency (To et al., 2013). However, as the findings of this study show, writers with higher lexical proficiency may produce texts with higher lexical density. To take this analysis further, the relationship of lexical density with other variables was identified.

In terms of the readability scores, students' essays addressed a proficient level of readers language-wise. As Xia, Kochmar, and Briscoe (2016) explain, the readability of a text is influenced by various factors such as the writer's style, lexical features of the text, syntactic dimensions, etc. Since a low readability score (in Flesch-Kincaid Grade) means that the text is easier to understand; yet, with academic texts, a text with a lower readability score does not address a particular group of readers, such as academics. Findings regarding the readability scores of student essays show that their texts were 
complex to be understood by readers having a high level language proficiency. It can be concluded here that textual and lexical features comply with each other in that EVP, lexical diversity, lexical density, and readability scores of a text may correspond to each other. However, lexical density may not be regarded as an indicator of text complexity in terms of language proficiency level.

One of the most important findings of this study was to reveal the relationship between the variables of metadiscourse use, lexical features of student essays, and the students' writing performance. Several significant relationships were identified. Initially, a positive relationship was found between total metadiscourse use and writing performance based on the students' research-based essays. When the related literature is reviewed, it is seen that no comprehensive study has been conducted to explore the relationship between metadiscourse use and the writing performance of the students except for the current study. Tavakoli, Dabaghi, and Khorvash (2010) found that explicit metadiscourse instruction to create awareness on the part of the students contributed to students' achievement in reading. Akin to this current study, a positive relationship was found between students' discourse use and composition scores (Cristina \& Martínez, 2004). Contributing to their study findings regarding discourse markers' use and student writing performance, the findings found in this study can be regarded as complementary.

Therefore, it is possible to conclude that both discourse and metadiscourse markers' use have positive relationships with the students' writing performance. Apart from this, there was a positive relationship between the readability scores of the students' essays and metadiscourse use. Since the readability score reflects the complexity, based on the number of sentences, syllables, and lexical features of a text, it was assumed that metadiscourse would also have a relationship with the readability scores of the texts. Similarly, a positive relationship was found between lexical diversity and metadiscourse in research-based essays. Dahme and Sastre (2015) reveal that academic texts are related to high lexical diversity and this feature is associated with advanced proficiency. This study showed that the lexical diversity, lexical proficiency, and metadiscourse use in student essays complement each other and feature the characteristics of writing for academic purposes. It is also worth noting here that lexical density had no relationship with metadiscourse, writing performance, lexical diversity, or readability scores of the students' research-based essays.

Writing is one of the most essential skills that should be developed for second/foreign language (L2) learners. Considering that writing even in one's native language requires extensive instruction, the enhanced importance of L2 writing instruction may be inferred. As writing is an action involving a number of elements such as the conveyance of one's thoughts and feelings, the use of lexical units, rhetoric, language use, text organization, cohesion and coherence, the development of writing skills for L2 learners is a multi-dimensional process. When the findings of this study are considered as a whole, it is possible to conclude that even when students are proficient users of the language, they may have difficulty in writing academically-acceptable texts and need to be given explicit instruction in metadiscourse to produce texts with unity, coherence and cohesiveness.

Although this research was not designed as an experimental study, the explicit metadiscourse instruction yielded a considerable effect on student writing. The analysis of metadiscourse in ELT students' research-based essays showed that, as novice research writers, students utilized both interactive and interactional metadiscourse in their texts following instruction in their writing program. Also, they employed a rich selection of lexical items with high density in their texts while also creating complex essays addressing academic readers. Thus, texts with appropriate metadiscourse usage also have higher lexical diversity, density, and readability. As a result of these significant findings, it is suggested that metadiscourse should be an integral part of the writing course curriculum since student achievements in writing, lexical diversity and readability relate positively with each other, increasing the students' overall writing quality. Thus, academics, course book writers, and program designers should take the significance of metadiscourse into account. They may prioritize the use and functions of metadiscourse in writing course content to equip learners better with 
the necessary writing skills for academic purposes.

\section{References}

Akbas, Erdem. "Exploring Metadiscourse in Master's Dissertation Abstracts: Cultural and Linguistic Variations across Postgraduate Writers." International Journal of Applied Linguistics and English Literature, vol. 1, no. 1, 2012, pp. 15-26.

Akbas, Erdem, and Çiler Hatipoğlu. "Metadiscourse Variations across Academic Genres: Rhetorical Preferences in Textual and Interpersonal Markers." Educational Sciences: Theory and Practice, vol. 18, 2018, pp. 767-75.

Akbulut, Fatma Demiray. "Effects of Teaching Collocations on Academic Writing." Turkish Online Journal of English Language Teaching (TOJELT), vol. 3, no. 2, 2018, pp. 64-82.

Akdemir, Ahmet Selçuk, and Aysel Eyerci. "Using Writing Templates as Materials to Improve Writing Skills in EFL Classes: An Experimental Study." Mersin University Journal of the Faculty of Education, vol. 12, no. 2, 2016, pp. 747-56.

Alavinia, Parviz, and Sahar Zarza. "Toward a Reappraisal of the Role of MD Markers in EFL Learners 'Perception of Written Texts." The Journal of Language Teaching and Learning, no. 2, 2012, pp. 1-23.

Almacioğlu, Gamze, and Zuhal Okan. "Genre-Based Writing for English Language and Literature Students: Interpersonal Relationship, Attitudes, Motivation and Achievement." Turkish Online Journal of English Language Teaching (TOJELT), vol. 4, no. 2, 2019, pp. 80-99.

Alotaibi, Hmoud S. "Metadiscourse in Dissertation Acknowledgments: Exploration of Gender Differences in EFL Texts." Educational Sciences: Theory \& Practice, vol. 18, no. 4, 2018, pp. 899-916.

Alotaibi, Ghuzayyil. "Grammatics for Teaching EFL Writing Skills : A Social Semiotic Systemic Functional Linguistics Approach." Turkish Online Journal of English Language Teaching (TOJELT), vol. 4, no. 1, 2019, pp. 19-32.
Amiryousefi, Mohammad, and Abbass Eslami Rasekh. "Metadiscourse: Definitions, Issues and Its Implications for English Teachers." English Language Teaching, vol. 3, no. 4, 2010, pp. 159-67.

Anwardeen, Nor Hafizah, et al. "An Analysis: The Usage of Metadiscourse in Argumentative Writing by Malaysian Tertiary Level of Students." English Language Teaching, vol. 6, no. 9, 2013, pp. 83-96.

Babanoğlu, M. Pınar. "A Corpus-Based Study on the Use of Pragmatic Markers as Speechlike Features in Turkish EFL Learners' Argumentative Essays." Procedia - Social and Behavioral Sciences, vol. 136, 2014, pp. 186-93.

Bal-Gezegin, Betül. "A Corpus-Based Investigation of Metadiscourse in Academic Book Reviews." Procedia - Social and Behavioral Sciences, vol. 232, 2016, pp. 713-18.

Bérubé, Nicolas, et al. "Words by the Tail: Assessing Lexical Diversity in Scholarly Titles Using Frequency-Rank Distribution Tail Fits." PLoS ONE, vol. 13, no. 7, 2018, pp. 1-31.

Can, Cem, and Fatma Yuvayapan. "StanceTaking through Metadiscourse in Doctoral Dissertations." International Journal of Languages' Education and Teaching, vol. 6, no. 1, 2018, pp. 128-142.

Çandarli, Duygu, et al. "Authorial Presence in L1 and L2 Novice Academic Writing: CrossLinguistic and Cross-Cultural Perspectives." Journal of English for Academic Purposes, vol. 20, 2015, pp. 192-202.

Cristina, Ana, and Lahuerta Martínez. "Discourse Markers in the Expository Writing of Spanish University Students." Ibérica, vol. 8, no. 1, 2004, pp. 63-80.

Cubukcu, Feryal. "Revisiting Metadiscourse Markers of the Language Learners in Academic Writing." Revista Romaneasca Pentru Educatie Multidimensionala, vol. 9, no. 2, 2017, pp. 36-47.

Dahme, Ana Pujol, and Moisés Selfa Sastre. "The Transition from University to Publication: Register and Interactional Metadiscourse Features in Immunology Research Written in 
Catalan and English." Iberica, vol. 2015, no. 30, 2015, pp. 155-82.

Davaei, Rezvan, and Alireza Karbalaei. “Interpersonal Metadiscourse in Compositions Written by Iranian ESP Students." European Online Journal of Natural and Social Sciences, vol. 2, no. 2, 2013, pp. 291-300.

Demir, Cüneyt. "Competence in Lexical Boosters and Nativeness in Academic Writing of English: The Possible Relation." Journal of Language and Linguistic Studies, vol. 13, no. 2, 2017, pp. 593-614.

Ebrahimi, Seyed Jamal. "The Role of Metadiscourse Markers in Comprehending Texts of Reading Comprehension Books Published in Iran and Oxford University Press." International Journal of Applied Linguistics and English Literature, vol. 7, no. 3, 2018, pp. 90-96.

Fareed, Muhammad, et al. "ESL Learners' Writing Skills: Problems, Factors and Suggestions." Journal of Education \& Social Sciences, vol. 4, no. 2, 2016, pp. 83-94.

Gholami, Javad, et al. "Metadiscourse Markers Misuses; A Study of EFL Learners' Argumentative Essays." Procedia - Social and Behavioral Sciences, vol. 98, no. 6, 2014, 2014, pp. 580-89.

Ginting, Siti Aisah. "Lexical Complexity on Descriptive Writing of Indonesian Male and Female EFL Learners." International Journal of English Linguistics, vol. 8, no. 3, 2018, pp. 297-302.

Gregori-Signes, Carmen, and Begoña ClavelArroitia. "Analysing Lexical Density and Lexical Diversity in University Students' Written Discourse." Procedia - Social and Behavioral Sciences, vol. 198, 2015, pp. 546556.

Hatipoğlu, Çiler, et al. Metadiscourse in Written Genres: Uncovering Textual and Interactional Aspects of Texts. Peter Lang, 2017.

Huda, Moh Choiru, and Willy Anugrah Gumilang. "The Effectiveness of Using Animation Clips in Teaching Writing." Turkish Online Journal of English Language Teaching (TOJELT), vol. 4, no. 2, 2019, pp. 63-79.
Hyland, Ken. Second Language Writing. Cambridge University Press, 2003.

Hyland, Ken. "Metadiscourse : Mapping Interactions in Academic Writing." Nordic Journal of English Studies, vol. 9, no. 2, 2010, pp. 125-143.

Hyland, Ken. "Teaching and Researching Writing." Applied Linguistics in Action Series, edited by Christopher N. Candlin and David R. Hall, Pearson, 2009.

Hyland, Ken, and Feng Kevin Jiang. "Is Academic Writing Becoming More Informal?." English for Specific Purposes, vol. 45, 2017, pp. 4051.

Hyland, Ken, and Polly Tse. "Metadiscourse in Academic Writing: A Reappraisal." Applied Linguistics, vol. 25, no. 2, 2004, pp. 156-77.

Ishikawa, Shin'ichiro. "Lexical Development in L2 English Learners' Speeches and Writings." Procedia - Social and Behavioral Sciences, vol. 198, 2015, pp. 202-210.

Johansson, Victoria. "Lexical Diversity and Lexical Density in Speech and Writing: A Developmental Perspective." Working Papers in Linguistics, vol. 53, 2008, pp. 61-79.

Jones, Jeremy F. "Using Metadiscourse to Improve Coherence in Academic Writing." Language Education in Asia, vol. 2, no. 1, 2011, pp. 1-14.

Kafes, Hüseyin. "An Intercultural Investigation of Meta-Discourse Features in Research Articles by American and Turkish Academic Writers." International Journal of Languages' Education and Teaching, vol. 5, no. 3, 2017, pp. 373-91.

Katelyn, Guichelaar. "Metadiscourse in Professional and Student Writing: A Corpus Study." Young Scholars in Writing, vol. 14, no. 1, 2017, pp. 6-16.

Kiliç, Mehmet. "Vocabulary Knowledge as a Predictor of Performance in Writing and Speaking: A Case of Turkish EFL Learners." Pasaa, vol. 57, 2019, pp. 133-164.

Kim, L.C., and J.M.H. Lim. "Metadiscourse in English and Chinese Research Article Introductions." Discourse Studies, vol. 15, no. 2, 2013, pp. 129-46. 
Koizumi, Rie. "Relationships between Text Length and Lexical Diversity Measures: Can We Use Short Texts of Less than 100 Tokens?." Vocabulary Learning and Instruction, vol. 1, no. 1, 2012, pp. 60-69.

Koizumi, Rie, and Yo In'nami. "Effects of Text Length on Lexical Diversity Measures: Using Short Texts with Less than 200 Tokens." System, vol. 40, no. 4, 2012, pp. 554-564.

Lin, Chi-yee. "Metadiscourse in Academic Writing: An Investigation of Graduate Students' MA Theses in Taiwan." Taiwan Journal of TESOL, vol. 2, no. 1, 2005, pp. 1-66.

Mansouri, Sara, et al. "Metadiscourse in Research Article Abstracts: A Cross Lingual and Disciplinary Investigation." Journal of Applied Linguistics and Language Research, vol. 3, no. 4, 2016, pp. 296-307.

McCarthy, Philip M., and Scoot Jarvis. "MTLD, Vocd-D, and HD-D: A Validation Study of Sophisticated Approaches to Lexical Diversity Assessment." Behavior Research Methods, vol. 42, no. 2, 2010, pp. 381-92.

McCarthy, Philip M., and Scott Jarvis. "VOCD: A Theoretical and Empirical Evaluation." Language Testing, vol. 24, no. 4, 2007, pp. 459-488.

Nasiri, Sina. "Exploring the Significant Role of Meta-Discourse in Academic Writing for a Discourse Community by Academic Members." International Journal of Research Studies in Education, vol. 2, no. 1, 2013, pp. 67-74.

Ozdemir, Neslihan Onder, and Bernadette Longo. "Metadiscourse Use in Thesis Abstracts: A Cross-Cultural Study." Procedia - Social and Behavioral Sciences, vol. 141, 2014, pp. 5963.

Ozturk, Gökhan, and Belgin Aydin. "English Language Teacher Education in Turkey: Why Do We Fail and What Policy Reforms are Needed?." Anadolu Journal of Educational Sciences International, vol. 9, no. 1, 2019, pp. 181-213.

Plakans, Lia, and Atta Gebril. "Exploring the Relationship of Organization and Connection with Scores in Integrated Writing
Assessment." Assessing Writing, vol. 31, 2017, pp. 98-112.

Rashtchi, Mojgan, and Maryam Baniardalani. "Lexical Reiteration Instruction through CLIL and L2 Composition Writing of Iranian High School Students." Applied Linguistics Research Journal, vol. 3, no. 4, 2019, pp. 4558.

Sağlamel, Hasan, and Mustafa Naci Kayaoğlu. “English Major Students' Perceptions of Academic Writing: A Struggle between Writing to Learn and Learning to Write." Journal of History Culture and Art Research, vol. 4, no. 3, 2015, pp. 37-52.

Sancak, Çiğdem. The Use of Transitions, Frame Markers and Code Glosses in Turkish EFL Learners' Opinion Paragraphs. Middle East Technical University, 2019.

Sun, Dongyun. "A Contrastive Analysis between English Vocabulary Profile and College English Wordlist." Theory and Practice in Language Studies, vol. 7, no. 9, 2017, pp. 729-736.

Tavakoli, Mansoor, et al. "The Effect of Metadiscourse Awareness on EFL Learners' Reading Comprehension: A Case of Iranian EFL Learners." English Language Teaching, vol. 3, no. 1, 2010, pp. 92-102.

To, Vinh, et al. "Lexical Density and Readability: A Case Study of English Textbooks." Internet Journal of Language, Culture and Society, vol. 37, 2013, pp. 61-71.

Uysal, Hacer Hande. "Argumentation across L1 and L2 Writing: Exploring Cultural Influences and Transfer Issues." Vigo International Journal of Applied Linguistics, vol. 9, no. 1, 2012, pp. 133-159.

Vasheghani Farahani, Mehrdad. "The Usage and Distributional Pattern of Metadiscourse Features in Research Articles in Applied Linguistics Based on Hyland 's Classification." Applied Linguistics Research Journal, vol. 2, no. 1, 2018, pp. 35-51.

Xia, Menglin, et al. "Text Readability Assessment for Second Language Learners." 11th Workshop on Innovative Use of NLP for Building Educational Applications, 2016, pp. 


\section{2-22.}

Yi, Jyi-yeon. "Defining Writing Ability for Classroom Writing Assessment in High Schools." Pan-Pacific Association of Applied Linguistics, vol. 13, no. 1, 2009, pp. 53-69.

Yüksel, H. Gülru, and Suzan Kavanoz. "Dimension of Experience: Metadiscourse in the Texts of Novice Non-Native, Novice Native and Expert Native Speaker." Advances in Language and Literary Studies, vol. 9, no. 3, 2018, pp. 104112.
Yuvayapan, Fatma. "Metadiscursive Nouns in Doctoral Dissertations: A Comparison of Native and Nonnative Speakers of English." Journal of Theory and Practice in Education, vol. 15, no. 1, 2019, pp. 74-87.

Zhang, Xiaoyan. "Reading-Writing Integrated Tasks, Comprehensive Corrective Feedback , and EFL Writing Development." Language Teaching Research, vol. 21, no. 2, 2015, pp. 217-240.

\section{Author details}

Ali Erarslan, Alanya Alaaddin Keykubat University, Turkey,Email ID: ali.erarslan@alanya.edu.tr. 